\title{
Sociocultural Adaptation and Program Management Strategies for International Doctoral Students of the "Confucius China Studies Program"
}

\author{
Yang Fan \\ Beijing Language and Culture University, Beijing, China \\ https:// orcid.org/0000-0002-2856-5957
}

\begin{abstract}
The purpose of this study was to understand the sociocultural adaptation status for international doctoral students of the "Confucius China Studies Program" (CCSP), as well as obtain suggestions from those students to the management of the program. This qualitative study applied an instrumental case study at a research site university in Beijing. Through distributing questionnaires to international students who participated in the program, as well as conducting one-to-one interviews with seven international students and two program management teachers, this study found that the sociocultural adaptation status of the international students of CCSP was generally high. The sociocultural adaptation status for doctoral students of the CCSP was analyzed from five aspects including interpersonal communication, academic performance, personal interest and social participation, environmental adaptation, and language proficiency. The interviewed international students proposed three suggestions to the management of the CCSP, including holding exchange and sharing activities for international doctoral students of the CCSP, compiling CCSP manual for international students of the program, and the establishment of a student writing center. This study also provides implications to administrators of the CCSP, international doctoral students, and policy-makers of this issue.
\end{abstract}

Keywords: "Confucius China Studies Program"; sociocultural adaptation; international doctoral students; program management

\section{Introduction}

Since China's acceded to the World Trade Organization in 2001, the number of international students admitted to China has been steadily on the increase. China has become the third largest study abroad destination country in the world and the largest in Asia (Ministry of Education of the People's Republic of China, 2018a). 
In recent years, the Chinese government has been paying close attention to the development of international student education in China. It has vigorously implemented various policies to recruit international students from other countries to come to study in China, such as the Chinese Government Scholarship, "One Belt and One Road" Scholarship, and the Confucius Institute Scholarship. According to the statistics from the Ministry of Education (MOE) in China, a total of 492,185 international students of various types from 196 countries and regions studied at 1,004 higher educational institutions in 31 provinces (including autonomous regions and municipalities) across China in 2018, with an increase of 3,013 , or $0.62 \%$, over 2017 (Ministry of Education of the People's Republic of China, 2019).

The Ministry of Education's Study in China Plan, introduced in October 2010, had proposed to build a system of international students studying in China services that is commensurate with China's global status and education scale (Ministry of Education of the People's Republic of China, 2010). In September 2018, the Ministry of Education in China issued a talent cultivation objective on the Quality Standards for International Students in Higher Education (Trial), which states that international students in China should have the awareness, knowledge, and skills to adapt to cultural diversity (Ministry of Education of the People's Republic of China, 2018b). The purpose of this study was to understand the current sociocultural adaptation status of international doctoral students from the "Confucius China Studies Program" (CCSP), and obtain suggestions from international students of CCSP at the program management level.

\section{Literature Review}

\subsection{Sociocultural adaptation theory}

Intercultural communication theorist Collen Ward (1996) classifies intercultural adaptation competence into two dimensions: psychological adaptation and sociocultural adaptation. Psychological adaptation is based on emotional responses, pointing to psychological health and life satisfaction in a cross-cultural environment, measured in terms of psychological health (Ward, 1996). Sociocultural adaptation is the adjustment of the sojourner to the local society, sufficient contact with local members, interaction, and negotiation with the local environment through the acquisition of culturally appropriate skills, based on the measurement of the difficulties experienced by the sojourner in the local society (Ward, 1996). The current academic classification of intercultural adaptation competence mainly follows Ward and Kennedy's view (Ward \& Kennedy, 1992). Research indicates that the factors that influence sojourners' adjustment can be classified into four categories: 1) social elements of the native culture: including social, economic, and cultural aspects; 2) local cultural factors: including crosscultural elements in social and economics; 3) individual characteristics: such as personality, previous sojourn experience, cross-cultural training experience, language ability, etc.; 4) individual and local cultural environment: includes factors such as length of cross-cultural contact, amount of contact with local groups, social support, and some other factors (Ward \& Kennedy, 1992). 


\subsection{Sociocultural adaptation of international students in China}

Research shows that the causes of a series of problems among international students in colleges and universities are closely related to cross-cultural adjustment (Chen, 2004). Lei and Gan (2004) from at Peking University investigated the cross-cultural adjustment status of 96 international students in Beijing and concluded that international students in China are a particular group of people who have more psychological problems and need to be targeted for primary prevention. Ding and Zhou's (2019) research found that the main reasons for the emergence of cross-cultural adjustment problems among international students in China include language barriers, lifestyle differences, social needs, and cultural differences.

The Chinese language level of international students is an essential factor that affects their sociocultural adaptation. A study on 68 international students in China found that interpersonal adaptation of international students with intermediate Chinese ability was significantly better than that of international students with primary Chinese ability (Li, 2009). There was no significant difference in interpersonal adaptation between international students with intermediate and advanced Chinese levels (Li, 2009). To a great extent, language difficulties hinder international students' learning process as well as social and cultural communication, make it difficult for them to participate in various academic activities at the university, also significantly affect their interpersonal adaptation situation.

The country of origin for international students is also an essential factor that affects their cultural adaptation. Ward, Bochner, and Furnham (2001) analyzed the relationship between cultural distance and cultural adaptation. Based on the results of their study, the cultural distance between European and American countries and China is considerable, so the level of cultural adaptation should be relatively low; the cultural distance between Japan and South Korea and China is small, so the level of cultural adaptation should be relatively high. However, a study conducted in nearly ten universities with 704 international students of all levels concluded that European and American students were more comfortable with Chinese people's attitudes toward them (Chen, Zhu \& Che, 2006). In contrast, students in Korea and Southeast Asian countries were sometimes uncomfortable with Chinese people's attitudes towards them (Chen, Zhu \& Che, 2006). The study shows that cultural distance is not the only factor that influences international students' adaptability, but also many other variables come into play. For example, because Chinese students are comparatively motivated to learn English, many Chinese students want to make friends with international students from countries where English is the native language. As a result, students from European and American English-speaking countries received relatively more social support in China compared to international students from other countries (Chen, Zhu \& Che, 2006). In terms of language adaptation, the level of adaptation of students from Korea and Japan is significantly higher than that of students from Europe, America, and other Southeast Asian countries, which is closely related to the social factors of international students' home cultures (Chen, Zhu \& Che, 2006). 
Other factors that affect the cultural adaptation of international students to study in China include the expectations of sojourners and the purpose of study in China. Students who come to China for cultural analysis and research have a deep love for China and a strong interest in Chinese culture. On the other hand, those who come to China for study and employment in China are optimistic about China's rapid development, economy, and numerous employment opportunities, and wish to work and live in China in the future. Those different motivations may have other effects on international students' adjustment during their time in China. Research suggests that international students' excessive expectations of the host country would increase their difficulties in intercultural adjustment. A better understanding of the host country could help international students to prepare for the problems they might face, thus forming the right expectations and reducing their problems in intercultural adjustment (Li, 2009). Also, other factors that influence international students' intercultural adaptability include subjective factors such as their characters, knowledge of the culture of the destination country, and their values ( $\mathrm{Zu}, 2015)$.

Much research on intercultural adaptation has been done in the field, but much of the existing research is based on international students study abroad in western countries. Philip Altbach (1991), an internationally renowned expert in comparative education states that the vast majority of the existing literature deals with the problems of adaptation and return of third-world students in industrialized countries, which are only a part of the total international student research. Due to cultural and national conditions differences between China and the west, western research results and literature cannot adequately explain the problem of international students' adjustment in China.

\section{Confucius China Studies Program (CCSP)}

The Confucius Institute Headquarters established the CCSP to help young scholars from all over the world understand China and Chinese culture, promote the study of sinology, enhance the sustainable development of the Confucius Institute, and contribute to the friendly relations between China and the peoples of other countries. CCSP is a high-end international exchange program launched by the Confucius Institute Headquarters in 2013, which aims to provide highquality training resources in China for overseas students, scholars, and elites from all walks of life who are studying China. The CCSP specializes in the humanities and social sciences which consists of six programs: the Joint Research PhD Fellowship, the PhD in China Fellowship, Understanding China Fellowship, Young Leaders Fellowship, Publication Grant, and the International Conference Grant (Confucius Institute Headquarters, 2020).

There are two types of doctoral student cultivation fellowships under the "Confucius China Studies Program": the Joint Research PhD Fellowship and the $\mathrm{PhD}$ in China Fellowship. The target population of this study is international students currently enrolled in the Joint Research PhD Fellowship and the PhD in China Fellowship. CCSP provides financial support for non-Chinese master's degree holders to study their doctoral degrees in China for three to four years. Applicants are required to reach at least level 5 in the Chinese Proficiency Test 
(HSK). Still, in the actual admission process, those with excellent Chinese proficiency are given priority under the same conditions. The significant subsidies of the program include living allowance and accommodation, research expenses, round-trip international travel expenses, tuition fees, training fees for Chinese universities, medical and accident insurance in China, and expenses for group activities and cultural experiences. The CCSP Joint Research PhD Fellowship for $\mathrm{PhD}$ students registered at foreign universities to study, conduct research, and write doctoral dissertations in China. According to the official website of the Confucius Institute Headquarters, applicants for the Joint Research $\mathrm{PhD}$ Fellowship is required to have a Chinese Proficiency Test (HSK) score of Level 3, but applicants with excellent Chinese proficiency are given priority. For the Joint Research PhD Fellowship, the main subsidized expenses are the same as students who participate in the $\mathrm{PhD}$ in China Fellowship for the period of studying in China for the doctoral degree (Confucius Institute Headquarters, 2020).

According to the Confucius Institute Headquarters' official website, there are 16 high-level universities in China participating in the PhD in China Fellowship by 2020, of which five universities are in Beijing, including Peking University, Renmin University of China, Beijing Normal University, Beijing Foreign Studies University, and Beijing Language and Culture University (Confucius Institute Headquarters, 2020).

The Ministry of Education (MOE) in China stressed the need to further implement the CCSP and expand the enrollment of outstanding young people from various countries to study doctoral degrees in China and to jointly cultivate doctoral students (Ministry of Education of the People's Republic of China, 2017). Research on international students studying for postgraduate degrees in Beijing under the CCSP would benefit their sociocultural adaptation among international students in China, as well as to cultivate high-level overseas talents for international Chinese language education. This study hopes to improve the management and serviceability of colleges and universities for international doctoral students in China. This study might also provide implications to policy-makers of the CCSP, thus promoting this international student community to play a more significant role in the international arena in the future.

\section{Research Methods}

\subsection{Research participants}

The research site was a university in Beijing, research participants were seven current doctoral international students who participated in the CCSP and two international student management teachers for this program. The seven participant students include five students who got the Joint Research PhD Fellowship and two students who received the PhD in China Fellowship. Among the seven students, there were four males and three females. The seven students came from seven different countries in Europe, Asia, and Africa. The majors they studied include International Chinese Language Education, Linguistics and Applied Linguistics, Foreign Linguistics and Applied Linguistics, and Literary Studies. Among the seven students, three students are between the ages of 26 to 29 years old, two students are between the ages of 36 to 39 years old, and two 
students are between the ages of 40-45 years old.

\subsection{Research questions}

Through conducting questionnaires and individual interviews with the nine research participants, this study focused on the following two research questions: 1. What are the sociocultural adaptation status for the currently enrolled CCSP international doctoral students during their study in China?

2. What are some suggestions from international doctoral students to the CCSP at the program management level?

\subsection{Research methods and procedures}

A qualitative study was used since qualitative methods typically produce a wealth of detailed information about a smaller number of people and cases to increase the depth of understanding of the cases and situations studied (Patton, 2002). This research applied an instrumental case study research design to understand the sociocultural adaptation status for international doctoral students of the CCSP (Merriam, 1990; Yin, 2003). An instrumental case study is applied when the intent of the case study is to understand a specific issue, problem, or concern and a case selected to best understand the problem (Stake, 1995). Through organizing and analyzing the information in the collected questionnaire, the researcher plans to understand the personal information, social and cultural adaptation status, and needs of international students at the doctoral level. Through semi-structured individual interviews, the researcher plans to gain further insight into the current situation and needs of international doctoral students' sociocultural adaptation status, as well as to understand the suggestions of international students on the program management level of the CCSP (Creswell, 2013).

Students enrolled in the CCSP is a relatively small population at the research site university, with a total of around 18 students enrolled in the program in the 2020 spring semester (including graduates in the class of 2020). Therefore, this study used a purposeful sampling strategy to select the intended participants of the study. The participants must be students who currently enrolled in the CCSP during the time of research. They must have been spent at least one semester at the research site university. The participants were recruited by contacting the program leader at the research site. After getting permission from the program leader, the researcher contacted ten international doctoral students of the CCSP through WeChat (a popular social networking software), and introduced the purpose of the study, research methods, confidentiality, and anonymity. Among the ten students, a total of seven international doctoral students agreed to participate in this study. The researcher sent the informed consent letter to all participants through WeChat and finalized nine research participants.

The researcher distributed an electronic version of the "Sociocultural Adaptation Questionnaire for CCSP International Students" to the international doctoral students. The questionnaire consists of two sections: the first section is the basic personal information of the participants such as their nationality, years of stay in China, and major; the second section of the questionnaire was adapted from Ward and Kennedy's (1999) version of the Sociocultural Adaptation Scale by Wilson 
(2013) to assess students' sociocultural adaptation status. The modified version highlights the academic performance dimension. It assesses the sociocultural adaptation status from five dimensions: interpersonal communication, academic performance, personal interest and social participation, environmental adaptation, and language proficiency (Wilson, 2013). To better understand the environmental adaptation dimension, the question "accommodate to food in the host country" was added to a total of 22 items (see Appendix 1). Scores are calculated by averaging the individual item scores, where higher scores represent greater competency in a new cultural environment (see Table 1). The internal consistency reliability of the adapted scale was 0.92 , and the test result was greater than 0.7, indicating that the reliability of the scale was high. All question options were in Likert-scale format, with five levels ranging from "completely inadaptable" to "very adaptable". After collecting the information of the participants, the researcher applied descriptive analysis to analyze the sociocultural adaptation of the participants to measure their sociocultural adaptation status.

After collecting the "Sociocultural Adaptation Questionnaire for CCSP International Students" from seven currently enrolled CCSP doctoral students, the researcher conducted one-to-one semi-structured interviews with the seven students and two CCSP student management teachers. Each interview was scheduled for 45 minutes, while the actual interview length ranged from approximately 35 minutes to 1 hour and 23 minutes under the interviewees' permission. All interviews were conducted in Chinese and were audio-recorded throughout. Since this study was conducted from June 2020 to August 2020 during the COVID-19 pandemic, all student interviews were conducted online via voice communication. The semi-structured interview protocols included open-ended questions for the "Confucius China Studies Program" International Doctoral Students and International Student Management Teachers. The sample interview question was, "please describe your adaptation in the aspect of interpersonal communication during your study of the program in China." The interview protocol designed for international doctoral students of the CCSP focused on five dimensions of the sociocultural adaptation of CCSP international doctoral students (see Appendix 2).

The interviews for program administrators were conducted through face-to-face communication. The interview protocol for administrators of the CCSP program was divided into four sections: personal information, professional quality, sociocultural adaptation status of students in the CCSP, as well as questions related to the CCSP (see Appendix 2). The researcher transcribed all interviews verbatim in Chinese. The nine interviews lasted about nine hours in total, and the length of the interview transcripts is about 94,000 words.

The researcher applied content analysis and thematic analysis to draw preliminary themes and conclusions of the study (Maxwell, 2013). After transcribing the interviews, the researcher repeatedly read through the transcripts several times and used NVivo 12.0 software for categorical aggregation and hierarchical coding (Chen, 2000). The questionnaires and transcripts were analyzed in Chinese and a large number of quotes were translated into English 
and included in the article. Combining information from the official websites of the research site and the introduction of the CCSP, the research questions were answered through questionnaires, individual interviews, and text analysis to generate themes. The researcher intends to ensure the trustworthiness of the study through rich and thick descriptions of the themes.

\section{Findings}

5.1 The sociocultural adaptation status for CCSP international doctoral students Through analyzing the collected data from the Revised Sociocultural Adaptation Scale (Table 1), the results of the seven participants' sociocultural adaptation ability were relatively competent. Among the seven participants, one student's sociocultural adaptation status is in the scale of "extremely competent" (5) during his study and life in the CCSP in China, the sociocultural adaptation status for four students are between the scales of "competent" and "extremely competent" (4-5), one student is "competent" (4) of sociocultural adaptation while study and live in China, and one student perceives his sociocultural adaptation status as "moderate" to "competent" (3-4).

Table 1: Results of the sociocultural adaptation scale

\begin{tabular}{|c|c|c|c|c|c|c|c|c|c|c|}
\hline 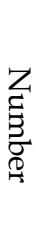 & & 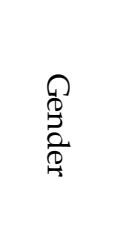 & & 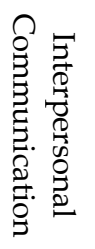 & 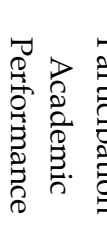 & 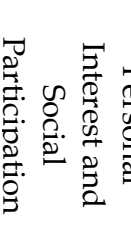 & 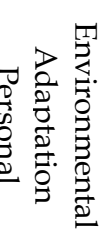 & 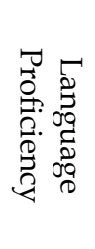 & 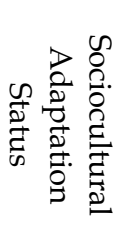 & 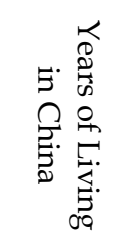 \\
\hline 1 & PCF & Female & $\begin{array}{l}\text { Literary } \\
\text { Studies }\end{array}$ & 4.14 & 4.75 & 4.25 & 5 & 5 & 4.55 & 12 years \\
\hline 2 & PCF & Female & $\begin{array}{l}\text { International } \\
\text { Chinese } \\
\text { Language } \\
\text { Education }\end{array}$ & 5 & 5 & 4.75 & 4.6 & 5 & 4.77 & 7 years \\
\hline 3 & PCF & Male & $\begin{array}{l}\text { International } \\
\text { Chinese } \\
\text { Language } \\
\text { Education } \\
\end{array}$ & 5 & 5 & 5 & 5 & 5 & 5 & 6 years \\
\hline 4 & PCF & Female & $\begin{array}{c}\text { Linguistics } \\
\text { and Applied } \\
\text { Linguistics }\end{array}$ & 4.14 & 4.75 & 4.5 & 4.4 & 4 & 4.36 & 4 months \\
\hline 5 & JRPF & Male & $\begin{array}{l}\text { International } \\
\text { Chinese } \\
\text { Language } \\
\text { Education }\end{array}$ & 3.71 & 4.25 & 2.75 & 4.8 & 5 & 4 & 6 months \\
\hline 6 & JRPF & Male & $\begin{array}{c}\text { Foreign } \\
\text { Linguistics } \\
\text { and Applied } \\
\text { Linguistics }\end{array}$ & 3.86 & 4 & 4.25 & 4.8 & 3.5 & 4.14 & 2 years \\
\hline 7 & PCF & Male & $\begin{array}{l}\text { Linguistics } \\
\text { and Applied } \\
\text { Linguistics }\end{array}$ & 3.57 & 3.75 & 3.75 & 3.8 & 4.5 & 3.77 & 8.5 years \\
\hline
\end{tabular}

Joint Research PhD Fellowship = JRPF

$\mathrm{PhD}$ in China Fellowship $=\mathrm{PCF}$

Combining interviews with international student administrators of the CCSP, the 
study found that the sociocultural adaptation level of international students in the CCSP is generally high. The first reason is that many international students in the program have completed their master's and even bachelor's degrees in China. Therefore, they already possess some sociocultural adaptation competence during their doctoral level of study. Among the seven international students who participated in the study, four students have lived in China for six years or more, accounting for $57.1 \%$ of the total number of students surveyed. Secondly, as a high-quality study abroad program from the Confucius Institute Headquarters, the international students admitted to the CCSP are elder than undergraduate international students, five of the seven students interviewed have about one to eight years of work experience, and five of them are married and have children. Those students have a mature and experienced way of coping with sociocultural adaptation. They can transfer the social interactions they have experienced in their home country to the country of study. During the interviews, two international student management teachers commented on the characteristics of the program students as having "high language and research proficiency, professional competence, all-around development, and leadership skills." In terms of sociocultural adaptability, they are able to use the perspective of "cultural relativism" to be aware of different standards of judgment and perceptions, and consciously change their reference standards in dealing with culture (Bennett, 1993). For example, international student 1 mentioned in the interview:

"Many international students come to China with the concepts of'the self and the other', and measure a country and its culture from his or her standard. I am not saying this is wrong, but this standard is not conducive to living in a foreign country for a long time. I feel that since I came to this country, I understand that this country has its own culture and some of its characteristics, and I accept these characteristics. But don't compare, 'oh, how China is like this, in my country...' You should look at a country's culture with a tolerant attitude, just understand and accept it."

\section{Interpersonal communication}

In terms of interpersonal communication, two of the seven international students evaluated their interpersonal communication adaptation in China as fully adapted. Another two international students felt that their level of adaptation in interpersonal communication was between adapted to very adapted, the rest of the three students was between average to adapted. During the interview, one student from Japan shared his challenges in adjusting to the mono-chronic culture while studying in China. He mentioned a typical case of being invited the night before a conference to give an oral presentation and another specific case of completing a 10,000 words research article within three weeks. The cases exemplify the discomfort in terms of time perspective and culture with the frequent changes in plans and schedules that characterize the monochronic culture in China (Hall \& Hall, 1990). According to Hofstede's Cultural Dimensions Theory, Japan as a distinctive culture with a high degree of uncertainty avoidance is characterized by a low tolerance for uncertainty and an expectation of clear regulations and planning systems (Hofstede, 2001).

In terms of interpersonal interactions, the international students in the program 
were able to maturely cope with the interactions between classmates and teachers in their daily lives. The international students in the CCSP doctoral program spoke highly of the educational management teachers at their research sites, which demonstrated the students' ability of empathy, for example, international student 2 stated:

"Me and the supermarket aunties, the security guard at our school, we're all good friends. I respect them a lot, I respect their labor. I think what I like most about Chinese people is those most ordinary people, it's their labor that makes China so glorious."

International student 5 noticed the lack of lunch breaks for staff members during the busy time and hopes to reduce the burden on some of the staff. Several other program students from different countries thanked the teachers work in all kinds of university departments to manage international students, with international student 1 stating:

"I would like to express my special thanks to the teachers in the Division of Confucius Institute Development, they have been helping us with all kinds of problems. Whatever big and small businesses we will go to them, academically related and unrelated. The teachers are especially patient to give us answers every time."

This study found that individual international students have some difficulties in adapting to the different customs, personal habits, and rest schedules patterns of different countries when it comes to roommates for on-campus accommodation. Indicating that while adjusting to Chinese society and culture, international students also need to adjust to the social and cultural habits and customs of different countries among the international student groups, especially when it comes to personality characteristics and living habits.

\section{Academic performance}

The doctoral dissertation topics of the CCSP include eight aspects related to China: 1) research on the Confucius Institute; 2) research on language, literature, and art, which involves sino-foreign studies or sino-foreign comparative studies; 3 ) research on history and philosophy, which involves sino-foreign comparative studies; 4) research on sociology, which involves Chinese minority studies, women's literature or women's status, Chinese society, Chinese rural areas, etc.; 5) political science and law studies; 6) economics studies; 7) education studies, and 8 international relations and cross-cultural studies. Among the above eight areas, international students often choose doctoral dissertation topics focusing on the second type of language, literature and art studies, and type four education studies, especially studies on language policy, overseas sinology, and localization of Chinese language education.

In terms of learning motivation, the international students in the CCSP are mainly intrinsically motivated, supplemented by extrinsic motivation, with a combination of instrumental motivation. Among the research participants, four students were intrinsically motivated. They were interested in their research directions, wanted to better understand China through the doctoral program, facilitate research data collection in China, and had the experience of studying 
abroad in China. Two international students were extrinsically motivated. They were attracted by the authority of the CCSP and the generous fellowship support provided by the program. One student was inspired by a combination of intrinsic and instrumental motivation, on the one hand, she would like to continually challenge and improve herself; on the other hand, she wants to have a better job position after finishing the program and back to her home country. The seven interviewed students learned about the program in several different ways, including recommendations from Chinese professors who came to study in Beijing, suggestions from mentors at foreign institutions or local Confucius Institute directors, and recommendations from their advisors while finishing their master's degree. The strong intrinsic motivation of international students is a good facilitator of their learning. For example, international student 2 is deeply interested in Chinese culture, and mentioned in the interview that her favorite course "Chinese Studies" is specifically designed for international students. The course introduces Chinese massage, Chinese medicine, tea ceremony, ancient poetry, and philosophy about Chinese culture, which satisfies the students' understanding and interest in China.

Of all the interviewed students, international student 1 and international student 3 believed that their biggest academic problem was self-discipline, including strict adherence to a prescribed schedule and time management. The student indicated that the low credit requirements of the program also impacted students' selfdiscipline. International student 6 noted that participation in reading groups has a positive effect on promoting peer interaction and academic achievement.

Studies have shown that field-independent learners are mostly analytical, prefer independent learning, and focus on abstract and objective factors. In contrast, field-dependent learners prefer to learn with others, focus on context and relationships, and expect guidance from teachers and peers (Brown, 2006). Brown's (2006) study suggested that field-independent and field-dependent learning styles were related to the sociocultural characteristics of international students. International student 7's elaboration of learning styles in the interviews is in line with Brown's findings that students from low-context cultures, highly industrialized countries, and individualistic cultures are inclined to have fieldindependent learning styles (Brown, 2006). However, field-independent or fielddependent learning styles are not absolute, and the following expressions reflect the shift from field-independent to the co-existing of field-independent and fielddependent learning styles of international student 7 :

"One of the big differences between undergraduate and master's study with a doctoral is that doctoral study centered on an individual... I sometimes write my dissertation behind closed doors, probably because I want to avoid socializing to make my dissertation better or to supervise my writing process. However, social interaction can sometimes be beneficial for my dissertation and research. So how to strike that balance, I think, is also a challenge during the doctoral program."

\section{Personal interest and social participation}

Combining the results of the interviews and the survey, five of the seven interviewed international students perceive that their personal interest and social 
participation had been accommodated and satisfied during their study in China. In terms of personal interest, thanks to the program's fellowship in the forms of living and research stipends and the convenient campus facilities at the research site, all international students generally felt that their personal interests in travel, sports, reading, calligraphy, music, and learning a new language other than Chinese were satisfied. The social involvement of international students showed a rich and varied character.

In terms of student activities on campus, international students in the CCSP have participated in the annual school gala, spoken at academic conferences as representatives of international students, hosted school events, and participated in the Association of International Student Union (AIU). In terms of social participation in off-campus activities, the Confucius Institute headquarters (current name Center for Language Education and Cooperation) has created lots of opportunities for students to participate in a variety of social activities and symposiums. During the interview, the international students mentioned that they have been invited by events at Chinese embassies, interviewed by China Central Television and People's Daily newspaper, selected as delegates in the International Chinese Language Education Conference, joined the open day ceremony from Confucius Institute Headquarters, enjoyed the cultural experiences (Chinese Studies Tours), participated in student exchanges between China and other countries, traveled throughout China, honored as international student representatives in the $70^{\text {th }}$ National Day parade, presented in the Doctoral Student Forum of the CCSP, and so on. Living in China also allowed the international students in the program to gain a better understanding of the Chinese language, culture, customs, and experiences of Chinese people's lives, such as finding an apartment, applying to the Internet, exercising at the gym, and shopping online.

Of the two international students who self-rated their involvement in social activities as low, one student chose to focus more on her doctoral dissertation and thus deliberately avoided or reduced socializing. The other student was less involved in on-campus and social activities due to his living off-campus and brought his children while studying in China, combined with the influence of a comparatively elder age. This indicates that age, family situation, length of study in China, and academic pressures of international students in the program had some degree of influence on their personal interests and social involvement.

\section{Environmental adaptation}

In terms of environmental adaptation, whether students live on or off-campus is an essential factor in influencing their sociocultural adaptation. As a result of the COVID-19 pandemic in the spring semester of 2020, the research site university waived the accommodation fees for international students who did not live on campus during that semester, which was practical assistance for international students. In terms of accommodation, six students chose to live on-campus during their stay in China because of the convenience of campus facilities, and one student decided to live off-campus for family reasons. One student thought that giving stipends as a package and self-pay accommodation fees is not as convenient as the Chinese Government Scholarship. The Chinese Government 
Scholarship, which is another competitive scholarship compared with the CCSP, directly waives students' on-campus accommodation fees. CCSP, on the other hand, provides students with a certain amount of stipend and students still need to pay for accommodations themselves, which adds a certain financial burden to the students' lives. However, two students in favor of this payment method since they were not required to live on campus and that they could bring their children and families to live in China with them, so they prefer this flexible way of accommodation. In terms of adapting to living in the city, one student suggested that the amount of stipend should take into account the price level of the city. The compensation provided by the CCSP would be sufficient for living in a small city in China, whereas in a large city like Beijing the compensation would be tight. Five students, on the other hand, felt that the living and academic stipends sponsored by the CCSP were generally sufficient to cover their life in Beijing.

\section{Language proficiency}

In the interviews, all interviewed students indicated that there were no significant obstacles in communicating with their Chinese teachers and classmates in Chinese, understanding the course content, and meeting the course credit requirements. In terms of Chinese listening, speaking, reading, and writing skills, one student said that it was difficult to fully understand the content when someone speaks fast in Chinese. In addition, three students indicated that the biggest obstacle in language proficiency was Chinese writing, especially dissertation writing. One advisor also required the student in the CCSP to publish one or two articles in Chinese. Some students said that their professors had commented that their writing was simple and lack of logic. They regarded the primary cause of the situation as a lack of specific training in Chinese writing. This was also agreed by the international student administration teachers, who were interviewed and believed that the obstacles in Chinese writing were influenced by the large difference between oral and written Chinese. It was more difficult for international students to write in Chinese. Besides, two students also believed that their academic research ability needs to be improved.

\subsection{Suggestions for management of CCSP CCSP experience sharing events for international doctoral students}

During the interviews, three of the international students suggested that the research site should provide opportunities for doctoral students to meet and know each other by organizing CCSP freshman orientations, CCSP experience sharing sessions, and scheduled seminars. Those events could invite current or graduated students of the CCSP to share their experiences in research methods, dissertation writing, study methods, and so on. Through senior students sharing experiences, freshman or sophomore doctoral students could gain learning experiences and form a professional learning community. International Student 7 expressed:

"I think the CCSP doctoral program could have a certain kind of experience sharing event. It could be in the form of a seminar or report session. I think one of the things I'm more concerned about is at the research level, including what problems my colleagues encountered, and what kind of process they experienced while conducting the research. I am 
not indicating the clean process written on the final dissertation, but the one that is quite rugged, the real process."

One student suggested that the experience sharing session could be conducted in small groups to provide opportunities for interactions among the presenter and the students for the best effectiveness.

International student 6 believes that dinner or orientation could be held when the CCSP students entered the program. Therefore, new students could get to know the program management teachers as soon as possible and close the distances among each other. This could also benefit the new students to adapt to their study and life in China. Several interviewed students also suggested that after the fifth or tenth anniversary of the international students' graduation, the research site could invite the international students to share their experiences, introduce their latest research, maintain contact with the university, and at the same time better publicize the CCSP. After the international students return to their home countries, it is important to strengthen the ties with the alumni of the program, promote the development and the output of the CCSP through various means.

\section{Compiling a manual for international students of the CCSP}

Many of the interviewed students said that they most often contacted the two teachers at the Division of Confucius Institute Development at the research institution. Teachers of the Division of Confucius Institute Development handled a series of matters including new student registration, program extensions, graduation, suspensions, end-of-term supervisors' evaluations, annual summaries, training plans, and a series of documents required by the program. Those teachers are also responsible for distributing living and academic stipends, airline ticket reimbursement, accommodation arrangements, and invitation letters for students and their families to obtain visas. The Division of Confucius Institute Development is also responsible for informing the students about specific information from the Confucius Institute Headquarters through WeChat.

When teachers in the Division of Confucius Institute Development were unable to answer the students' questions, they would contact other departments. Departments such as the International Student Administration Office, students' graduate schools, and the Accommodation Center could help resolve problems related to new student registration, visas, course selection, and so on. During the interviews, two interviewees mentioned that they often encountered the problem of not knowing which teacher in which department to contact for specific questions and through what means. International student 4 and international student 6 suggested making a detailed manual for international students of the CCSP based on the existing manual for all international students from the International Student Administration Office. The manual for CCSP could explain in more detail the procedures involved in the program, such as orientation, class selection, accommodation, etc., so that students would know which specific department to contact, whom to contact, and by what means. On the other hand, the manual could reduce the workload and pressure of international student staff, avoid repeated inquiries from different students on the same issue, and improve working efficiency. 


\section{Establishing a student writing center}

In response to the academic writing difficulties raised by a number of international students, international student 7 noted that the current methods of learning academic writing include self-study, advisor's guidance, and help from colleagues. However, he mentioned that seeking support from Chinese colleagues caused some trouble and added workload for them. He wished to get more professional and efficient help with writing. International student 7 suggested that the university could create a student writing center at the research site institution. The writing center would be staffed with professional teachers or graduate students to tutor international students in Chinese academic writing. In addition, currently enrolled Chinese students and university faculty members could also get assistance from the Writing Center. Possible services the center could provide include text proofreading, editing, essay formatting, workshops about writing skills, as well as bilingual writing tutoring in both Chinese and English. Regular lectures, seminars, salons on academic writing, and books on writing skills could also facilitate students' learning. The Writing Center could set up a support group for essay writing, where monthly meetings can be held to discuss the progress of their reading and dissertation writing, as well as the problems they may face during their writing process. Through the creation of a student writing center, the Chinese writing skills of international students, not only for students in the CCSP but also the international student group in the research site in general, could be effectively improved.

\section{Conclusions}

This study focuses on understanding the sociocultural adaptation of international students in the CCSP through questionnaires and one-on-one interviews, as well as their suggestions on program management. All research aims have been accomplished through this study. It is found that the social and cultural adaptability of international students in the CCSP is generally high. This study provides implications to policy-makers and the research site university to hold exchange and sharing activities for international doctoral students of the CCSP, compile CCSP manual for international students of the program, and establish a student writing center at the research site university. This study also has several limitations, the first limitation is the small sample size of the participants. Because of the relatively small population of students enrolled in the CCSP in the research site university, it was difficult to recruit a large number of students to participate in this study. The second limitation is that because of the COVID-19 pandemic, all student interviews were conducted online via WeChat voice communication. The third limitation of the study is that if possible, a triangulation of the research methods such as observation and document analysis could be used to enhance the trustworthiness of the study. As a high-level international student program in China, understanding the social and cultural adaptability of international doctoral students of the CCSP during their study in China, obtaining suggestions and demands of the international students in program management could help promote the standardization and long-term effectiveness of international student management and contribute to the development of international student affairs in Chinese universities. 
Funding: This research program is supported by the Science Foundation of Beijing Language and Culture University (supported by "the Fundamental Research Funds for the Central Universities") (Approval number: 19YBB21).

\section{References}

Altbach, P. G. (1991). Impact and adjustment: Foreign students in comparative perspective. Higher Education, 4, 305-323. Retrieved from https://link.springer.com/article/10.1007/BF00132723

Bennett, M. J. (1993). Towards a developmental model of intercultural sensitivity. In R. M. Raige (Ed.), Education for the intercultural experience. Yarmouth, ME: Intercultural Press.

Brown, H. D. (2006). Principles of language learning and teaching (5th ed.). White Plains, New York: Pearson Longman.

Chen, H., Zhu, M., \& Che, H. S. (2006). Zai Beijing gaoxiao de waiguo liuxuesheng shiying yinsu yanjiu [A study of adaptation factors for foreign students in Beijing universities]. Qingnian yanjiu [Journal of Youth Studies], 27-36.

Chen, X. M. (2000). Zhi de yanjiu fangfa yu shehui kexue yanjiu [Qualitative research methods and social science research]. Beijing: Educational Science Press.

Chen, X. M. (2004). Sojourners and "Foreigners": A study on Chinese students' intercultural interpersonal relationships in the United States. Educational Science Press.

Confucius Institute Headquarters. (2020). Confucius China Studies Program. Retrieved from http://ccsp.chinese.cn/index.html

Creswell, J. W. (2013). Qualitative inquiry and research design: Choosing among five approaches (3rd ed.). Thousand Oaks, CA: Sage.

Ding, S. Y., \& Zhou, Z. C. (2019). Kuawenhua shijiaoxia yidaiyilu yanxian guojia liuxuesheng guanli tanxi [An analysis of the management of international students study abroad in China from countries along the "Belt and Road" from a cross-cultural perspective]. Nanyang ligong xueyuan xuebao [Journal of Nanyang Institute of Technology], 3, 80-84.

Hall, E. T., \& Hall, M. R. (1990). Understanding cultural differences: Germans, French and Americans. Yarmouth, ME: Intercultural Press.

Hofstede, G. (2001). Culture's consequences (2nd ed.). Beverly Hills, CA: Sage.

Lei, L. Y., \& Gan, Y. Q. (2004). Laihua liuxuesheng de kuawenhua shiying qingkuang diaocha [Survey on the sociocultural adaptation status for international students study abroad in China]. Zhongguo xinli weisheng zazhi [Chinese Mental Health Journal], 10, 729.

Li, P. (2009). Liuxuesheng kuawenhua shiying xianzhuang yu guanli duice yanjiu [Research on the current situation of cross-cultural adaptation and management strategies of international students in China]. Zhejiang shehui kexue [Zhejiang Social Science], 5, 114-119.

Merriam, S. B. (1990). Case study research in education: A qualitative approach. San Fransico, CA: Jossey-Bass Publishers.

Maxwell, J. A. (2013). Qualitative research design: An interactive approach (3rd ed.). Thousand Oaks, CA: Sage.

Ministry of Education of the People's Republic of China. (2010). Study abroad in China program. Retrieved from http://www.moe.gov.cn/srcsite/A20/moe_850/201009/t20100921_108815.htm 1

Ministry of Education of the People's Republic of China. (2017). Letter of response to the proposal No. 0580 (Education No. 059) of the fifth session of the twelfth National 
Committee of the CPPCC. Retrieved from http:/ / www.moe.gov.cn/jyb_xxgk/xxgk_jyta/jyta_gjhb/201803/t20180302_32 8506.html

Ministry of Education of the People's Republic of China. (2018a). National statistical bulletin on the development of education in 2017. Retrieved from http://www.moe.gov.cn/jyb_sjzl/sjzl_fztjgb/201807/t20180719_343508.html

Ministry of Education of the People's Republic of China. (2018b). The Ministry of Education's circular on the issuance of "Higher education for international students in China quality specification (trial)" notice. Retrieved from http://www.moe.gov.cn/srcsite/A20/moe_850/201810/t20181012_351302.htm

Ministry of Education of the People's Republic of China. (2019). Statistics on international students studying in China in 2018. Retrieved from http://www.moe.gov.cn/jyb_xwfb/gzdt_gzdt/s5987/201904/t20190412_37769 2.html

Oxford, R. L. (1996). Language learning strategies around the world: Cross-cultural perspectives. Manoa, HI: University of Hawaii Press.

Patton, M. Q. (2002). Qualitative research and evaluation methods (3rd ed.). Thousand Oaks, CA: Sage.

Stake, R. (1995). The art of case study research. Thousand Oaks, CA: Sage.

Ward, C. (1996). Acculturation. In D. Landis \& R. Bhagat (Eds.), Manual of intercultural training (pp. 124-147). Thousand Oaks, CA: Sage.

Ward, C., \& Kennedy, A. (1992). Locus of control, mood disturbance, and social difficulty during cross-cultural transitions. International Journal of Intercultural Relations, 16(2), 175-194. doi:10.1016/0147-1767(92)90017-0

Ward, C., \& Kennedy, A. (1999). The measurement of sociocultural adaptation. International Journal of Intercultural Relations, 4, 659-677. doi:10.1016/S01471767(99)00014-0

Ward, C., Bochner, S., \& Furnham, A. (2001). The psychology of culture shock. New York: Routledge.

Wilson, J. (2013). Exploring the past, present and future of cultural competency research: The revision and expansion of the sociocultural adaptation construct [Unpublished Doctoral dissertation]. Victoria University of Wellington.

Yin, R. K. (2003). Case study research: Design and method (3rd ed.). Thousand Oaks, CA: Sage.

$\mathrm{Zu}$, X. M. (2015). Kuawenhua jiaoji [Intercultural communication]. Beijing: Foreign Language Teaching and Research Press. 


\section{Appendix}

\section{Questionnaire on the Sociocultural Adaptation Status of International Doctoral Students of the "Confucius China Studies Program"}

Dear student,

Thank you so much for agreeing to participate in this study. I am conducting a survey to understand the sociocultural adaptation of international doctoral students in China under the Confucius China Studies Program. The questionnaire will be anonymous and all information will be kept confidential. The obtained data will only be used for this study. Please read each question carefully and select the option that best fits your situation.

Your completion of the questionnaire will be very helpful to my research, thank you for your participation and support!

\section{Section 1: Basic Personal Information}

1. First three letters of your name:

2. Gender: $\square$ Male $\square$ Female

3. Nationality:

4. Age:

5. Major of study in the CCSP:

6. How long have you been living in China so far:

7. Which type of CCSP are you in:

$\square$ Joint Research PhD Fellowship $\square \mathrm{PhD}$ in China Fellowship

8. HSK level:

9. Years of study in the doctoral program:

10. Native language:

11. Besides your native language, how many languages can you speak and what are the languages:

12. Before joining the CCSP, do you have any work experience? If so, what was your job and how many years have you been working?

13. Before joining the CCSP, do you have any experience in studying and working in overseas countries? If so, which country have you been living, and for how many years?

14. Before joining the CCSP, what is your major(s) during your undergraduate and master's degree of study:

15. Have you ever suffered from economic difficulties during your study of the CCSP? What is your primary income during your study at the CCSP?

16. Have you got married during your study at the CCSP? Do you have any children? 


\section{Section 2: Sociocultural Adaptation Scale}

Thank you for answering the basic information questions in Part I. In Part II, the questions will focus on understanding your intercultural adaptation while studying in China. There are five level options for each question and you will be asked to select the one that best fits your situation. The options on the left are not at all appropriate for your situation and the options on the right best fits your situation. To ensure the accuracy and validity of the data, please answer the questions based on your real situation.

Thank you for your cooperation and understanding!

\section{SCAS-R}

\section{Revised Sociocultural Adaptation Scale}

Living in a different culture often involves learning new skills and behaviors. Thinking about life in [country], please rate your competence at each of the following behaviors ( $1=$ Not at all competent; $5=$ Extremely competent).

\begin{tabular}{|c|c|c|c|c|c|}
\hline 1. Building and maintaining relationships. & 1 & 2 & 3 & 4 & 5 \\
\hline 2. Managing my academic/work responsibilities. & 1 & 2 & 3 & 4 & 5 \\
\hline 3. Interacting at social events. & 1 & 2 & 3 & 4 & 5 \\
\hline 4. Maintaining my hobbies and interests. & 1 & 2 & 3 & 4 & 5 \\
\hline 5. Adapting to the noise level in my neighborhood. & 1 & 2 & 3 & 4 & 5 \\
\hline $\begin{array}{l}\text { 6. Accurately interpreting and responding to other } \\
\text { people's gestures and facial expressions. }\end{array}$ & 1 & 2 & 3 & 4 & 5 \\
\hline $\begin{array}{l}\text { 7. Working effectively with other students/work } \\
\text { colleagues. }\end{array}$ & 1 & 2 & 3 & 4 & 5 \\
\hline 8. Obtaining community services I require. & 1 & 2 & 3 & 4 & 5 \\
\hline 9. Adapting to the population density. & 1 & 2 & 3 & 4 & 5 \\
\hline 10. Understanding and speaking [host language]. & 1 & 2 & 3 & 4 & 5 \\
\hline $\begin{array}{l}\text { 11. Varying the rate of my speaking in a culturally } \\
\text { appropriate manner. }\end{array}$ & 1 & 2 & 3 & 4 & 5 \\
\hline $\begin{array}{l}\text { 12. Gaining feedback from other students/work } \\
\text { colleagues to help improve my performance. }\end{array}$ & 1 & 2 & 3 & 4 & 5 \\
\hline $\begin{array}{l}\text { 13. Accurately interpreting and responding to other } \\
\text { people's emotions. }\end{array}$ & 1 & 2 & 3 & 4 & 5 \\
\hline $\begin{array}{l}\text { 14. Attending or participating in community } \\
\text { activities. }\end{array}$ & 1 & 2 & 3 & 4 & 5 \\
\hline 15. Finding my way around. & 1 & 2 & 3 & 4 & 5 \\
\hline 16. Interacting with members of the opposite sex. & 1 & 2 & 3 & 4 & 5 \\
\hline
\end{tabular}




\begin{tabular}{|c|c|c|c|c|c|}
\hline $\begin{array}{l}\text { 17. Expressing my ideas to other students/work } \\
\text { colleagues in a culturally appropriate manner. }\end{array}$ & 1 & 2 & 3 & 4 & 5 \\
\hline 18. Dealing with the bureaucracy. & 1 & 2 & 3 & 4 & 5 \\
\hline 19. Adapting to the pace of life. & 1 & 2 & 3 & 4 & 5 \\
\hline 20. Reading and writing [host language]. & 1 & 2 & 3 & 4 & 5 \\
\hline $\begin{array}{l}\text { 21. Changing my behavior to suit social norms, } \\
\text { rules, attitudes, beliefs, and customs. }\end{array}$ & 1 & 2 & 3 & 4 & 5 \\
\hline 22. Accommodating to food in the host country. & 1 & 2 & 3 & 4 & 5 \\
\hline
\end{tabular}

\section{SCAS-R Scoring}

SCAS-R items are based on a Likert scale of 1 (= Not at all competent) to 5 (= Extremely competent). Scores are calculated by averaging the individual item scores, where higher scores represent greater competency (skills or behaviors) in a new cultural environment.

Scores for each of the SCAS-R subscales may also be calculated:

Interpersonal Communication: Items 1, 3, 6, 11, 13, 16, 21

Academic Performance: Items 2, 7, 12, 17

Personal Interest and Social Participation: Items 4, 8, 14, 18

Environmental Adaptation: Items 5, 9, 15, 19, 22

Language Proficiency: Items 10 and 20

Appendix 2

\section{Interview Protocol}

("Confucius China Studies Program" International Doctoral Students)

\section{Interview questions:}

1. Please tell us why you joined the "Confucius China Studies Program" (hereinafter referred to as "the program").

2. Please describe the training model and graduation requirements (e.g. credits, dissertation, other requirements, etc.) of the program.

\section{Intercultural adaptation:}

3.What do you think was the biggest challenge you encountered during the program?

4.What do you think is the most important thing you have achieved during the program?

5. Please describe your adaptation in the aspect of interpersonal communication during your study of the program in China.

6. Please describe your adaptation of academic performance during your study of the program in China. 
7. Please describe in what ways the needs of your personal interest and social participation have been accommodated and met during your participation in the program in China.

8. How would you evaluate the level of your adaption to the local environment during your study and life in the program?

9. How would you evaluate your Chinese language proficiency while participating in the program?

\section{Program Management strategies for the CCSP:}

10. How do you think the Confucius Institute headquarters has helped you in your study and life during your participation in the program?

11. How do you think the international student affairs administrators at your university have helped you in your study and life during the program?

12. If possible, what advice do you have for the university's administration and services to better serve future international students participating in the program? 13. If possible, what suggestions do you have for the policies of international students coming to study in China for the betterment of the program in the future? 14. If possible, what advice would you give to future international students participating in the program to help them better adapt to their study and life in China?

15.What are some questions that I hadn't thought of, but that you think I should know about or should be explored.

Thank you for your support of this interview and research!

\section{Interview Protocol}

\section{(International Student Management Teachers)}

\section{Basic personal information}

1. Your field of study:

2. Number of years you have worked in international student management:

3. Did you study or work overseas before working in the field of international student management:

4. If you have overseas experience, the country in which you previously studied or worked overseas is: and the number of years you have worked or studied overseas is:

\section{Interview questions}

1. Please tell a little bit about the main tasks of your work in the "Confucius China Studies Program".

The professionalism of international student managers:

2. Did you have any professional training or work experience before engaging in the management of international students, if so, can you tell us about it?

3. What are the main administrative challenges for international doctoral students in the CCSP?

4. Have you ever felt overwhelmed in managing international students? Were there times when you felt fulfilled with this work? 


\section{Intercultural adaptation of doctoral students:}

5. The sociocultural adaptation dimension of intercultural adaptation consists of five aspects: interpersonal communication, academic performance, personal interest and social participation, environmental adaptation, and language adaptation. In your work, have you encountered any problems with any of the above dimensions of intercultural adjustment among the doctoral students of the CCSP? If so, can you tell us about them?

6. Has your department taken any measures or organized any activities to improve the intercultural adaptation of international doctoral students under the CCSP during their study in China, and if so, what measures and activities have been taken and organized?

7. What do you think are the differences and characteristics of the international doctoral students in the CCSP compared to other international students?

8.What do you think are the differences between international students at the doctoral level and other undergraduate or non-degree international students in terms of learning and adjustment during their study in China?

9. In your opinion, what measures can universities take in the future to improve the intercultural adaptability of international doctoral students in the CCSP?

\section{The "Confucius China Studies Program":}

10. Do you have any suggestions for the development of the CCSP at the policy and management level?

11. Do you have any advice for international students who are participating in the CCSP to improve their adjustment to study and life in China?

12. Are there any issues that I haven't thought of, but you think I should know about or discuss?

Thank you for your support of this interview and research! 